\section{Devices and developments}

Paul M. Grant

Applled Superconductivlty. Editor-in-chief Roger B. Poeppel. Elsevier. 12/yr. North, Central and South America $\$ 649$ (institutional), rest of the world $£ 435$ (institutional),

"OF making many books there is no end; and much study is a weariness of the flesh" (Ecclesiastes 12:12). In our present

conductivity by Y. S. Cha et al., an excellent detailed analysis of critical current measurements relevant to wire 'embodi-

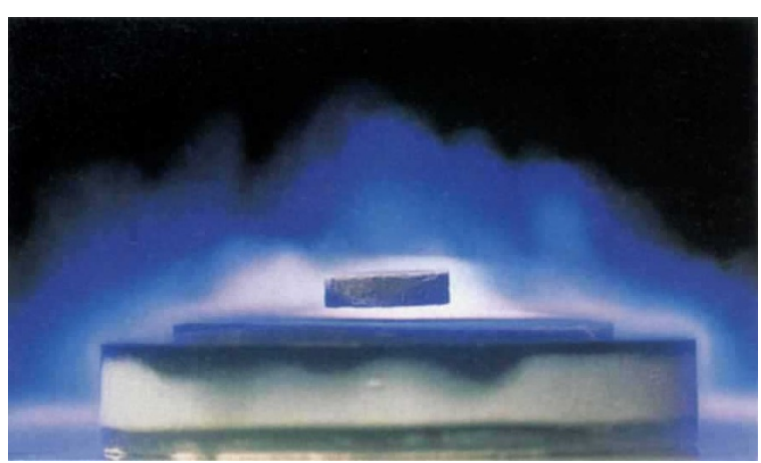
ments', provides an exam-

is ple of the kind of submission that the editors need to encourage should they indeed wish to redirect their journal in such a direction.

One final small point: the cover of Applied Superconductivity displays the striking three-dimensional rendition of the crystal structure of $\mathrm{La}_{2} \mathrm{CuO}_{4}$ created by staff of the IBM Science Centre in Winchester, United Kingdom.

Magnetic levitation by a superconducting ceramic.

age of information overload, this Old Testament adage (the Hebrew sages could have added wearisome to the spirit as well) echoes throughout almost every professional community whenever a new journal appears to compete for individual attention and library shelf space, both in increasingly short supply. Nonetheless, they keep coming, and in the opening months of 1993 the first issues of Applied Superconductivity, one more addition to the vast Pergamon stable (now itself owned by Elsevier), hit the newsstands of science. Is another journal really needed in a field whose workers struggle daily to dig themselves out from under the current avalanche of papers?

The answer is a definite maybe. Well, actually a no - those engaged in research into superconducting applications are going to continue to submit their most important results to well established and highly visible journals such as Applied Physics Letters, perhaps even the muchmaligned yet ever-venerable Physical Review Letters. Among the newer journals, IEEE Transactions on Applied Superconductivity seems to have captured much of the readership targeted by Pergamon, especially those pursuing the development of electronic devices. Of seven major university and industrial institutions in the San Francisco Bay Area that run programmes in applied superconductivity, only two subscribe to Applied Superconductivity. All subscribe to Applied Physics Letters and IEEE Transactions.

To be fair, a very qualified yes may also be in order. There are so far no journals that focus solely on wire development and its application to large-scale power and magnetic devices. The paper appearing in the January 1994 issue of Applied Super. uous by my absence. So it was my early experience with Supramolecular Chemistry.

With the experimental phase now behind it, I have to admit that here is a new journal for communications and papers - with reviews being "published only on an occasional basis" - that is fulfilling its mission as stated by the editors: that is, "to provide a timely presentation outlet for high quality work that bridges the traditional disciplines but which retains a chemical orientation". And sure enough, one finds good-quality publications across the spectrum of the wellknown receptors (for example, cyclodextrins, crown ethers, calixarenes, cyclophanes, cryptands, spherands and so on) as well as highly original contributions to phenomenologically based (membranes, vesicles, sensors) and conceptually orientated (self-assembly, self-organization, self-replication and so on) research in the supramolecular domain.

The names of the leaders in the field are dotted throughout the early volumes and the presentation is of a uniformly high standard. Even colour turns up in occasional issues, although the plates are divorced from the publications they refer to and are relegated to the final entries just before the contents on the back cover of the journal. The overall style of the journal is user-friendly, with "Index Abstracts" featuring a graphical component. Supramolecular chemistry is a highly visual art form. Indeed, one can often predict the authorship of a publication from a glimpse of the pictures contained therein.

I also applaud the decision of the editors to feature one of the publications in each issue on the front cover. This practice, which should never be taken too seriously by established members of the community, does much to heighten everyone's interest in a journal. The encouragement that making the front cover brings to a young researcher has to be seen to be believed.

Above all, it is the part that this new journal is now playing in helping to reunite the once highly divided discipline of chemistry that is one of its main strengths. For some strange reason, perhaps scientifically based, the chemistry of the covalent bond has encouraged chemists to fragment into smaller and smaller groups with increasingly limited goals and horizons. At least at this early stage in its development, the chemistry of the noncovalent bond is encouraging chemists to come together and speak not only to each other but also to other scientists with greater authority. This is what supramolecular chemistry in its broadest sense is all about.

Fraser Stoddart is in the School of Chemistry, University of Birmingham, Edgbaston, Birmingham B15 2T, UK. 